\author{
Mpho Bosupeng ${ }^{1}$ \\ University of Botswana, Gaborone, Botswana
}

\title{
The Effect of Exports on Carbon Dioxide Emissions: Policy Implications
}

\begin{abstract}
The purpose of this study is to explore long run affiliations between exports and carbon dioxide emissions. This paper examines thirty-seven countries over the period 1960 to 2010 and uses the Toda and Yamamoto causality approach to investigate the direction of causal links. The results reveal that carbon dioxide emissions Granger cause exports in the following economies: Bolivia, Canada, Costa Rica, Morocco, Austria and Ireland. Nonetheless, the reverse causality proved that exports Granger cause carbon dioxide emissions in twelve economies. Furthermore, the study registered bidirectional causal links between exports and carbon dioxide emissions in the USA and Burkina Faso. We conclude that countries should consider exports market demand, energy consumption and economic growth in their attempts to reduce carbon dioxide emissions.
\end{abstract}

Keywords: exports, carbon dioxide emissions, Toda and Yamamoto causality, energy consumption

JEL: O44

\section{Introduction}

In national income accounting, exports play a vital role in determining national output. This has led economists to coin economic growth hypotheses, namely: the growth-driven exports hypothesis and the export-led growth hypothesis. The concern is that many economies are driven by exports, which works against controlling emissions. Asian countries, particularly China and India, are often defined as export-led economies. The glitch with 
export-led growth economies is that they tend to be substantial carbon dioxide emitters. Countries such as China and India face pressure to limit carbon dioxide discharges. China proposed a $40-45 \%$ reduction in carbon dioxide emissions by 2025 . According to Gregg et al. [2008], China is the largest emitter of carbon dioxide globally and India reportedly has a high emissions growth of carbon dioxide. As both China and India became major economic players, their high growth has had a major impact on the environment. Carbon dioxide is not the only gas that has detrimental effects. There are other gases liberated, such as sulphur dioxide, which is associated with respiratory malfunctions and acid rain. Individuals living near mining industries have also reported early blindness as a side effect of sulphur dioxide emissions. The harmful outcome of excess carbon dioxide is the greenhouse effect, as carbon dioxide traps the sun's heat resulting in an upsurge in the earth's temperatures. Ecologists have predicted that in the long run, this process can lead to a dramatic change in the world's climate. Economies that rely on food exports (such as rice, maize, and cocoa) will be affected adversely by this alteration. China has been active in soliciting new technology to combat emissions through emissions trading system, and Malaysia stepped forward by introducing green taxation to limit emissions. Even though carbon levies have proved to be effective, their ramifications on economic growth are not impressive.

Manufacturing industries are limited by carbon taxation, which often leads to a decline in economic growth, especially in countries such as China and India. Most existing studies have focused on economic growth, carbon dioxide emissions and energy consumption. Few studies have attempted to address the direct relationship between exports and carbon dioxide emissions. Even though this relationship has not been studied in depth, the long run association of the variables carries robust implications for energy consumption, emissions reduction and economic growth. Many economies face a dilemma: either they reduce carbon dioxide emissions or divert their resources to economic growth.

It is important to identify the main drivers of an economy before attempting to reduce emissions. If an economy is driven by exports as the main source of income, then careful measures should be enforced to ensure that economic growth is not hindered. Where, however, a country does not produce high-tech exports, income could be accrued from sources such as tourism, education fees, income tax or rent. In that case, it would be easier to enforce policies reducing carbon dioxide emissions - such as green taxation. Countries that export minerals - such as copper (e.g. Zambia) and diamonds (e.g. Botswana) - have to be more cautious with the magnitude of emissions as well as practicality in the use of minerals. It is therefore imperative to understand the relationship between exports and carbon dioxide emissions. Hypothetically, if a country intends to reduce emissions, policy makers can enforce energy conservation regulations, which should lead to low emissions. However, other macroeconomic variables such as unemployment may then rise. For instance, an administrator operating a local coal plant may then need less workers to operate energy supply projects. 
This paper proposes that exports rely on energy, which results in high energy demand. Consequently, exports growth increases energy consumption, resulting in high carbon dioxide emissions. By using the transitive property in mathematics, we can infer that exports production drives carbon dioxide emissions. This paper contributes to the literature by examining the long term relationship between exports and carbon dioxide emissions. The question is, why is the relationship between exports and carbon dioxide evaluated in this study?

We posit two main reasons: First, this relationship is important in determining market response to associated exports. The expectation is that if carbon dioxide emissions are induced by exports, it implies demand for manufactured products. This creates a rise in energy consumption leading to the production of more carbon dioxide. Second, this relationship facilitates the evaluation of the prudent use of resources, based on the presumption that exports induce an increase in carbon dioxide emissions and demand for energy. Economies need to determine proper consumption channels of fossil fuels to avoid complete depletion. This means they have to consider exports production and rising carbon dioxide emissions without exhausting energy sources. An alternative will be to carry out a production process that will produce more energy with fewer emissions. However, this situation will differ depending on a country's energy sources. The investigation applies the Toda and Yamamoto [1995] causality process to analyse causal links between economic variables. The rest of this paper is structured as follows: first, we review the literature, followed by description of methodology and empirical test results. We then discuss our results and reach conclusions.

\section{Literature Review}

The existing literature generally focuses on energy consumption, economic growth and carbon dioxide emissions. Alshehry and Belloumi [2015] confirmed significant long run relationships between energy consumption, energy prices, carbon dioxide emissions and economic growth in Saudi Arabia. Their study relied on the Johansen multivariate cointegration technique. The results showed that energy consumption stimulated economic growth and carbon dioxide emissions. This means that controlling energy consumption will impinge on economic development and the magnitude of emissions. The authors suggested that macroeconomic policies intended to reduce energy consumption and carbon dioxide emissions many not adversely affect Saudi Arabia’s economic growth.

However, Wang [2013] suggested that upsurges in carbon dioxide emissions are caused by output growth in the USA and China. The results are reasonable, particularly for China. China's exponential economic growth has been attributed to exports. In this method of economic growth, industries also expand resulting in more carbon dioxide emissions. Today China is the largest emitter of carbon dioxide in the world. According 
to Wang [2013] economies can reduce their emissions by minimizing energy intensity. Fossil fuels usually have a high energy value but their emissions are robust. Economies therefore need to determine an equilibrium function that maximizes output and minimizes emissions simultaneously. Similarly, Omri [2013] found that energy consumption is the main source of carbon dioxide emissions in MENA countries.

In another study by Zhang and Cheng [2009], a causality effect from energy consumption to carbon dioxide emissions was observed in China. That study further showed that both carbon dioxide emissions and energy consumption had no significant impact on economic growth. The authors suggested that since economic growth is not influenced by energy consumption or carbon emissions, China can carry energy policies that reduce emissions without affecting economic growth. These results were welcomed by China because it is under intense pressure to cut emissions and continue economic growth. The issue is the relationship between economic variables, which is not fixed. Over time empirical analysis can show that economic growth is directly influenced by energy consumption and carbon dioxide emissions. If that is the case, policy makers need to revisit energy policies frequently. In the Turkish economy, carbon dioxide emissions had a significant bearing on energy consumption [Soytas, Sari, 2009]. As with China, no significant relationship between output and emissions was observed. Loganathan et al. [2014] revealed bidirectional causal links between carbon tax and carbon dioxide emissions in Malaysia. The authors noted that economic growth induced an increase in carbon dioxide emissions. However, green taxation stimulated economic growth in the long run. Zhixin and Ya [2011] also suggested that carbon tax could stimulate economic growth in eastern parts of China.

It is important to note that there are other drivers of energy consumption such as population density [Jafari et al., 2012]. In China, carbon dioxide emissions growth was also exacerbated by the needs of transport sector. Xu and Lin [2015] showed that between 1980 and 2012 carbon dioxide emissions in China's transport sector increased approximately 9.7 times, with an average annual growth rate of $7.4 \%$. Exports production has been associated with high carbon dioxide emissions. Chang et al. [2013] examined the ramifications of energy exports and economic growth using the bias-corrected least square model for five Caucasus economies (Azerbaijan, Armenia, Georgia, Russia and Turkey). The study proved that economic growth is brought by high energy exports and globalization. Kahrl and Roland-Holst [2008] observed that exports are the largest source of energy demand growth in China.

To summarize the literature review, the main driver of carbon dioxide emissions is energy consumption as the majority of economies use fossil fuels for energy and exports production. Fossil fuels are also used to generate electric power. Additionally, automobiles use fossil fuels such as gasoline during internal combustion, which adds to carbon dioxide emissions. In China, energy consumption and carbon dioxide emissions were found to have no significant effects on economic growth. The literature shows that exports generate an increase in energy demand. Few studies have investigated whether exports 
affect the magnitude of carbon dioxide emissions. This research aims to determine the direct relationship between exports and carbon dioxide emissions over the period 1960 to 2010 using the Toda and Yamamoto [1995] causality approach.

We postulate that exports increase energy consumption (high demand), leading to high carbon dioxide emissions. Denoting exports as $E_{t}$; energy demand as $D_{e}$; energy consumption as $\mathrm{C}_{e}$ and carbon dioxide emissions as $\mathrm{CO}_{2}$. The relationship can be represented as:

$$
E_{t} \uparrow \rightarrow D_{e} \uparrow \rightarrow C_{e} \uparrow \rightarrow \mathrm{CO}_{2} \uparrow
$$

Logically, we can evaluate the direct relationship between exports and carbon dioxide emissions as represented by the following anticipated relation:

$$
E_{t} \uparrow \rightarrow \mathrm{CO}_{2} \uparrow
$$

In summary, the literature fails to address the direct relationship between exports and carbon dioxide emissions. This paper aims to contribute to the existing literature by validating causal links between exports and carbon dioxide emissions using the Toda and Yamamoto [1995] causality approach.

\section{Data Sources and Methods}

This paper surveys the relationship between income accrued from exports and carbon dioxide emissions. The data was obtained from a web source named The Global Economy (http://www.theglobaleconomy.com/). The data source contains a number of different macroeconomic variables. This study examines thirty-seven different economies over the period 1960 to 2010. Exports were selected in this study because they are important in export-led growth economies and should not be dissociated with carbon emissions from manufacturing industries. Consideration was given to net exports; however that will necessitate reducing exports data with imports. Focusing on exports is crucial as they are directly linked with manufacturing industries that require energy, and generate emissions. Many economies, in consequence, are concerned with rising carbon dioxide emissions from exports production. Another plausible variable is GDP

Carbon dioxide emissions were measured in tonnes $(t)$ while income from exports was measured in billions of US dollars. The actual data were converted to natural logarithms to perform our analysis. It is imperative that the data set is examined for unit roots. The Augmented Dickey Fuller test [Dickey, Fuller, 1979] was selected to test for stationarity of the variables. The testing procedure of the $\mathrm{ADF}$ is derived from the following generalized model: 


$$
\Delta y_{t}=\alpha+\beta_{t}+\gamma y_{t-1}+\delta \Delta y_{t-1}+\cdots+\delta_{p-1} \Delta y_{t-p+1}+\varepsilon_{t}
$$

The model applied in this study is:

$$
\therefore \Delta y_{t}=\alpha+\beta_{t}+\gamma y_{t-1}+\sum_{i=1}^{k} \delta_{i} \Delta y_{t-1}+\varepsilon_{t} .
$$

The definition of terms is as follows: the regression constant is $\alpha$ and $\beta$ is the coefficient of the time trend. Following Asemota and Bala [2011], $\varepsilon_{t}$ was defined as the white noise error term. Eviews 7 was used to test the stationarity of the series. Table 1 shows the results of the Augmented Dickey Fuller test.

\begin{tabular}{|c|c|c|}
\hline Country & Carbon dioxide & Exports \\
\hline Barbados & $-2.596114^{*}$ & $-1.615445^{\star}$ \\
\hline Bolivia & $-2.152875^{\star}$ & $-1.530077^{\star}$ \\
\hline Canada & $-1.664362^{*}$ & $-0.630576^{*}$ \\
\hline Chile & $-2.029469^{*}$ & -4.250026 \\
\hline Colombia & $-2.330316^{*}$ & $-2.092489^{\star}$ \\
\hline Costa Rica & $-2.613937^{*}$ & $-1.456228^{\star}$ \\
\hline Ecuador & $-1.064043^{\star}$ & $-1.604317^{\star}$ \\
\hline Guatemala & $-1.906877^{\star}$ & $-1.920948^{*}$ \\
\hline Honduras & $-2.377123^{*}$ & $-2.147829^{*}$ \\
\hline Mexico & $-0.491741^{\star}$ & $-1.088600^{*}$ \\
\hline Trinidad \& Tobago & -4.531461 & $-1.940269^{*}$ \\
\hline USA & $-2.813025^{\star}$ & $-1.558457^{\star}$ \\
\hline Uruguay & $-2.173077^{\star}$ & $-2.121801^{\star}$ \\
\hline Venezuela & $-3.751882^{*}$ & $-2.227163^{*}$ \\
\hline Benin & $-3.201790^{*}$ & $-1.773505^{\star}$ \\
\hline Burkina Faso & $-3.445926^{*}$ & $-2.248234^{*}$ \\
\hline Gabon & $-2.593545^{*}$ & $-1.607382^{*}$ \\
\hline Ivory Coast & $-1.890845^{\star}$ & $-1.782691^{*}$ \\
\hline Kenya & $-3.501770^{*}$ & $-1.637232^{*}$ \\
\hline Madagascar & $-3.228420^{*}$ & $-3.254481^{*}$ \\
\hline Mauritania & $-2.611152^{*}$ & $-1.452321^{*}$ \\
\hline Morocco & $-1.612630^{*}$ & $-2.294836^{*}$ \\
\hline Niger & $-3.501239^{*}$ & $-1.812805^{*}$ \\
\hline
\end{tabular}

\section{TABLE 1. Augmented Dickey Fuller (ADF) test results}




\begin{tabular}{|l|l|l|}
\hline \multicolumn{1}{|c|}{ Country } & Carbon dioxide & Exports \\
\hline Nigeria & $-2.174025^{*}$ & $-2.213271^{*}$ \\
\hline Rep. Congo & $-2.737782^{*}$ & $-2.070720^{*}$ \\
\hline Senegal & -5.463986 & $-1.904137^{*}$ \\
\hline South Africa & $-1.237836^{*}$ & $-2.122675^{*}$ \\
\hline Australia & $-1.243064^{*}$ & $-2.178340^{*}$ \\
\hline Austria & $-2.591350^{*}$ & $-1.628513^{*}$ \\
\hline Belgium & $-2.626649^{*}$ & $-1.847323^{*}$ \\
\hline France & $-2.805379^{*}$ & $-1.291667^{*}$ \\
\hline Ireland & $-1.770027^{*}$ & $-2.043268^{*}$ \\
\hline Italy & -4.622520 & $-0.689090^{*}$ \\
\hline Spain & $-1.106530^{*}$ & $-0.711161^{*}$ \\
\hline Sweden & $-2.749000^{*}$ & $-1.331897^{*}$ \\
\hline Switzerland & $-3.874268^{*}$ & $-1.150608^{*}$ \\
\hline UK & $-3.056598^{*}$ & $-1.728430^{*}$ \\
\hline
\end{tabular}

Note:

The ADF test statistics are reported above. The critical values for exports and $\mathrm{CO}_{2}$ are as follows: $-[4.152511]$ is the critical value at $1 \%$ level; $-[3.502373]$ is the critical value at $5 \%$ level and $-[3.180699]$ is the critical value at $10 \%$ level.Superscripts $\left({ }^{*}\right)$ indicate statistical significance at $1 \%, 5 \%$, and $10 \%$ critical levels respectively. The results are based on the model: $\Delta y_{t}=\alpha+\beta_{t}+\gamma y_{t-1}+\sum_{i=1}^{k} \delta_{i} \Delta y_{t-1}+\varepsilon_{t}$. Eviews 7 was used to compute the ADF unit root test. The null hypothesis for the test is "series $\mathrm{x}$, has a unit root".

Source: own elaboration.

The above results show that the data is non-stationary at different levels ( $1 \%, 5 \%$ and $10 \%)$. This is proved by ADF statistics, which are greater than the critical values. The following series were stationary: Trinidad and Tobago, Senegal, Italy and Chile.

\section{The Toda and Yamamoto [1995] Approach to Granger Causality}

The aim of this paper is to investigate the long run relationship between exports and carbon dioxide emissions. The expectation is that as income escalates from exports production, carbon dioxide emissions will also intensify. The Granger causality test [Granger, 1969] was not selected because not all data in this study are non-stationary. Granger causality also has several limitations. First, if the variables under consideration are driven by a common third process with different lags, there is a possibility of failing to reject the alternative hypothesis of Granger causality. In addition, Granger causality is often based on the assumption that causal relations are a result of cointegration. The advantage of the Toda and Yamamoto [1995] approach is that the VAR's formulated in the 
levels can be estimated even if the processes may be integrated or cointegrated of an arbitrary order. Wolde-Rufael [2005] observed that the Toda and Yamamoto [1995] approach fits a standard vector autoregressive model in the levels of the variables. In consequence, this minimizes the risks associated with the likelihood of mistakenly identifying the order of integration of the series [Mavrotas, Kelly, 2001]. The literature has developed a number of cointegration methods following the contributions of Saikkonen and Lütkepohl [2000a, 2000b]; Johansen and Juselius [1990]; Johansen [1988, 1991]; Granger [1981]; Granger and Weiss [1983]; Engle and Granger [198]); Granger and Engle [1985]; Stock [1987]; Phillips and Durlauf [1986]; Phillips and Park [1986]; Phillips and Ouilaris [1986]; Stock and Watson [1987]; Park [1990, 1992]; Phillips and Hansen [1990]; Hovarth and Watson [1995]; Saikkonen [1992] and Elliot [1998]. Most of these studies are based on the assumption that cointegrated variables will be attracted to each other in the long run. Toda and Yamamoto [1995] noted that if economic variables are not cointegrated then the VAR should be estimated in first-order differences of the variables to validate the conventional asymptotic theory. In consequence, the Toda and Yamamoto [1995] approach is applicable even if the VAR may be stationary, integrated of an arbitrary order or cointegrated of an arbitrary order.

This study applies the Toda and Yamamoto [1995] approach as discussed by Wolde-Rufael [2005]. The testing procedure starts by augmenting the correct VAR order $k$ by the maximal order of integration $d_{\max }$ [Wolde-Rufael, 2005]. Following this, a $\left(k+d_{\max }\right)^{\text {th }}$ order of the VAR is estimated and the coefficients of the last lagged $d_{\max }$ vector are ignored [Caporale, Pittis, 1999; Rambaldi, Doran, 1996; Rambaldi, 1997; Zapata, Rambaldi, 1997]. Denote exports as $L X$ and assign carbon dioxide emissions as $L E$. The VAR system of the variables can now be depicted as:

$$
\begin{gathered}
L X_{t}=\alpha_{0}+\sum_{i=1}^{k} \alpha_{1 i} L X_{t-i}+\sum_{j=k+1}^{d_{\text {max }}} \alpha_{2 j} L X_{t-j}+\sum_{i=1}^{k} \varnothing_{1 i} L E_{t-i}+\sum_{j=k+1}^{d_{\text {max }}} \varnothing_{2 j} L E_{t-j}+\lambda_{1 t} \\
L E_{t}=\beta_{0}+\sum_{i=1}^{k} \beta_{1 i} L E_{t-1}+\sum_{j=k+1}^{d_{\text {max }}} \beta_{2 j} L E_{t-j}+\sum_{i=1}^{k} \delta_{1 i} L X_{t-i}+\sum_{j=k+1}^{d_{\text {max }}} \delta_{2 j} L X_{t-j}+\lambda_{2 t}
\end{gathered}
$$

\section{Empirical Results}

Eviews 7 was used to carry out the Toda and Yamamoto [1995] approach to causality. The results show that carbon dioxide emissions have a significant influence on exports in the following economies: Bolivia, Canada, Costa Rica, Morocco, Austria and Ireland. These countries registered $\rho$-values less than the $5 \%$ critical level, suggesting that we have 
to reject the null hypothesis of non-causality. The reverse causality proved that an increase in exports induces an upsurge in carbon dioxide emissions in twelve countries, namely: Barbados, Ecuador, Mexico, Trinidad and Tobago, Kenya, Niger, Senegal, South Africa, Australia France, Spain, and the UK. Burkina Faso and the USA are the only economies that exhibited bidirectional causal links between carbon dioxide emissions and exports. Table 2 presents the results of the Toda and Yamamoto [1995] causality test.

TABLE 2. Carbon dioxide emissions and exports causality test results

\begin{tabular}{|c|c|c|c|c|c|}
\hline \multirow{2}{*}{ Country } & \multicolumn{2}{|c|}{$\mathrm{CO}_{2 \mathrm{t}} \Rightarrow \mathrm{EXP}_{t}$} & \multicolumn{2}{|c|}{$\mathrm{EXP}_{\mathrm{t}} \Rightarrow \mathrm{CO}_{2 \mathrm{t}}$} & \multirow{2}{*}{$\begin{array}{c}\text { Direction of } \\
\text { causality }\end{array}$} \\
\hline & Chi-sqr. & $\rho$-value & Chi-sqr. & $\rho$-value & \\
\hline Barbados & 2.005239 & 0.36690 & 6.381130 & $0.04110^{\star *}$ & $\mathrm{EXP} \Rightarrow \mathrm{CO}_{2}$ \\
\hline Bolivia & 7.291862 & $0.02610^{* *}$ & 1.351835 & 0.50870 & $\mathrm{CO}_{2} \Rightarrow \mathrm{EXP}$ \\
\hline Canada & 6.446382 & $0.03980^{* *}$ & 0.286805 & 0.86640 & $\mathrm{CO}_{2} \Rightarrow \mathrm{EXP}$ \\
\hline Chile & 0.519315 & 0.77130 & 2.647394 & 0.26610 & $\mathrm{CO}_{2} \nRightarrow \mathrm{EXP}$ \\
\hline Colombia & 2.169650 & 0.33800 & 2.880352 & 0.23690 & $\mathrm{CO}_{2} \nRightarrow \mathrm{EXP}$ \\
\hline Costa Rica & 10.21758 & $0.00600^{\star *}$ & 4.118511 & 0.12750 & $\mathrm{CO}_{2} \Rightarrow \mathrm{EXP}$ \\
\hline Ecuador & 2.041143 & 0.36040 & 6.583239 & $0.03720^{\star *}$ & $\mathrm{EXP} \Rightarrow \mathrm{CO}_{2}$ \\
\hline Guatemala & 0.026599 & 0.98680 & 0.052719 & 0.97400 & $\mathrm{CO}_{2} \Leftrightarrow \mathrm{EXP}$ \\
\hline Honduras & 5.596279 & 0.06090 & 0.242957 & 0.88560 & $\mathrm{CO}_{2} \Leftrightarrow \mathrm{EXP}$ \\
\hline Mexico & 3.419529 & 0.18090 & 6.610879 & $0.03670^{* *}$ & $\mathrm{EXP} \Rightarrow \mathrm{CO}_{2}$ \\
\hline Trinidad \& Tobago & 3.149437 & 0.20710 & 8.392555 & $0.01510^{\star *}$ & $\mathrm{EXP} \Rightarrow \mathrm{CO}_{2}$ \\
\hline USA & 7.218769 & $0.02710^{\star *}$ & 25.61381 & $0.00000^{* *}$ & $\mathrm{CO}_{2} \Leftrightarrow \mathrm{EXP}$ \\
\hline Uruguay & 0.069966 & 0.96560 & 3.675269 & 0.15920 & $\mathrm{CO}_{2} \Leftrightarrow \mathrm{EXP}$ \\
\hline Venezuela & 1.758524 & 0.41510 & 3.860566 & 0.14510 & $\mathrm{CO}_{2} \Leftrightarrow \mathrm{EXP}$ \\
\hline Benin & 2.058602 & 0.35730 & 1.142425 & 0.56480 & $\mathrm{CO}_{2} \Leftrightarrow \mathrm{EXP}$ \\
\hline Burkina Faso & 7.193731 & $0.02740^{* *}$ & 14.53042 & $0.00070^{* *}$ & $\mathrm{CO}_{2} \Leftrightarrow \mathrm{EXP}$ \\
\hline Gabon & 0.233718 & 0.88970 & 2.919493 & 0.23230 & $\mathrm{CO}_{2} \Leftrightarrow \mathrm{EXP}$ \\
\hline Ivory Coast & 0.713915 & 0.69980 & 0.512895 & 0.77380 & $\mathrm{CO}_{2} \Leftrightarrow \mathrm{EXP}$ \\
\hline Kenya & 0.501944 & 0.77800 & 0.969556 & $0.03070^{\star *}$ & $\mathrm{EXP} \Rightarrow \mathrm{CO}_{2}$ \\
\hline Madagascar & 1.333662 & 0.51330 & 3.720299 & 0.15560 & $\mathrm{CO}_{2} \Leftrightarrow \mathrm{EXP}$ \\
\hline Mauritania & 0.209209 & 0.90070 & 4.052287 & 0.13180 & $\mathrm{CO}_{2} \Leftrightarrow \mathrm{EXP}$ \\
\hline Morocco & 10.55467 & $0.00510^{\star *}$ & 1.354187 & 0.50810 & $\mathrm{CO}_{2} \Rightarrow \mathrm{EXP}$ \\
\hline Niger & 2.919915 & 0.23220 & 10.55591 & $0.00510^{* *}$ & $\mathrm{EXP} \Rightarrow \mathrm{CO}_{2}$ \\
\hline Nigeria & 1.201666 & 0.54840 & 1.379865 & 0.50160 & $\mathrm{CO}_{2} \Leftrightarrow \mathrm{EXP}$ \\
\hline Rep. Congo & 1.037234 & 0.59530 & 4.374555 & 0.11220 & $\mathrm{CO}_{2} \Leftrightarrow \mathrm{EXP}$ \\
\hline Senegal & 1.109092 & 0.57430 & 17.95886 & $0.00010^{* *}$ & $\mathrm{EXP} \Rightarrow \mathrm{CO}_{2}$ \\
\hline
\end{tabular}




\begin{tabular}{|c|c|c|c|c|c|}
\hline \multirow{2}{*}{ Country } & \multicolumn{2}{|c|}{$\mathrm{CO}_{2 \mathrm{t}} \Rightarrow \mathrm{EXP}_{t}$} & \multicolumn{2}{|c|}{$\mathrm{EXP}_{\mathrm{t}} \Rightarrow \mathrm{CO}_{2 \mathrm{t}}$} & \multirow{2}{*}{$\begin{array}{l}\text { Direction of } \\
\text { causality }\end{array}$} \\
\hline & Chi-sqr. & $\rho$-value & Chi-sqr. & $\rho$-value & \\
\hline South Africa & 2.990252 & 0.22420 & 12.44452 & $0.00200^{\star *}$ & $\mathrm{EXP} \Rightarrow \mathrm{CO}_{2}$ \\
\hline Australia & 2.101392 & 0.34970 & 7.324624 & $0.02570^{* *}$ & $\mathrm{EXP} \Rightarrow \mathrm{CO}_{2}$ \\
\hline Austria & 6.771280 & $0.03390^{* *}$ & 0.408732 & 0.81520 & $\mathrm{CO}_{2} \Rightarrow \mathrm{EXP}$ \\
\hline Belgium & 1.830550 & 0.40040 & 3.247633 & 0.19710 & $\mathrm{CO}_{2} \nRightarrow \mathrm{EXP}$ \\
\hline France & 3.703136 & 0.15700 & 10.93244 & $0.00420^{* *}$ & $\mathrm{EXP} \Rightarrow \mathrm{CO}_{2}$ \\
\hline Ireland & 6.009591 & $0.04950^{* \star}$ & 1.686128 & 0.43040 & $\mathrm{CO}_{2} \Rightarrow \mathrm{EXP}$ \\
\hline Italy & 3.099718 & 0.21230 & 0.563756 & 0.77730 & $\mathrm{CO}_{2} \Leftrightarrow \mathrm{EXP}$ \\
\hline Spain & 1.708833 & 0.42550 & 0.996845 & 0.60750 & $\mathrm{CO}_{2} \Leftrightarrow \mathrm{EXP}$ \\
\hline Sweden & 1.267304 & 0.53070 & 19.21899 & $0.00010^{* *}$ & $\mathrm{EXP} \Rightarrow \mathrm{CO}_{2}$ \\
\hline Switzerland & 3.525526 & 0.17160 & 0.242681 & 0.88570 & $\mathrm{CO}_{2} \Leftrightarrow \mathrm{EXP}$ \\
\hline UK & 4.461519 & 0.10740 & 13.72530 & $0.00100^{* *}$ & $\mathrm{EXP} \Rightarrow \mathrm{CO}_{2}$ \\
\hline
\end{tabular}

Note:

EXP represents Exports. The arrows signify the direction of causation. $\Rightarrow$ implies causality in a given direction; $\Leftrightarrow$ implies a bidirectional causal relationship; $\nLeftarrow$ implies that there is no causality between the variables. The test was carried out at $5 \%$ significant level. The null hypothesis $\left(\mathrm{H}_{0}\right)$ is that a given variable does not Granger cause the other (non-causality). Note that $\rho$-values less than the $5 \%$ critical level $(\rho<0.05)$ represent causality in a given direction. The null hypothesis is therefore rejected for $\rho$-values less than the significant level. Asterisks ${ }^{* *}$ ) represent a causal relationship at the $5 \%$ significant level. Eviews (7) was used to carry out the Toda-Yamamoto approach to Granger causality.

S o u r c e: own calculations.

\section{Implications and Conclusion}

This paper examined the direct relationship between exports and carbon dioxide emissions using the Toda and Yamamoto causality procedure for the period 1960 to 2010. The results show that carbon dioxide induces exports in the following economies: Bolivia, Canada, Costa Rica, Morocco, Austria and Ireland. The results further show that carbon dioxide emissions are associated with rising exports in Barbados, Ecuador, Mexico, Trinidad and Tobago, Kenya, Niger, Senegal, South Africa, Australia, France, Spain and UK. The results of the causality test further show that there are bidirectional affiliations between exports and carbon dioxide for Burkina Faso and the USA.

Our results have some implications for policy making. In economies where exports induce carbon dioxide emissions, the relationship between exports and carbon dioxide emission, may be explained by a high demand for manufactured goods. Such demand creates upsurges in energy consumption leading to the production of more carbon dioxide. This does not mean that exports are the only link to rising energy demand and carbon dioxide emissions. The entire export production process, including value adding 
processes up to the finished product, could be responsible for a rise in carbon dioxide emissions. Reducing carbon dioxide emissions in this case will not be drastic and without complications. First, one has to consider alternative energy sources and their efficiency in the production of exports. Energy consumption for exports differs from commodity to commodity. In this scenario an economy will have to create objective functions that will satisfy market demand and produce reasonable carbon dioxide emissions. This may explain why China's efforts in reducing carbon dioxide emissions have not been successful because the economy also has to meet market demand for various goods. Nonetheless, in the case where carbon dioxide induces an increase in exports there are several possible explanations. This could mean that an economy is producing high energy exports, for example automobiles. This creates high energy demand leading to more carbon dioxide emissions. In this case economic growth will be dependent on fulfilling market demand by manufacturing high energy exports. In practical terms, reducing carbon dioxide drastically may not be beneficial for an economy. There are several objectives to consider. Every economy is different but economic growth is a top priority for all. To better understand the role of exports on emissions, they should be disaggregated rather than using their cumulative value. This would help reveal which exports specifically fulfil the high energy exports market for a given economy. In conclusion, there is a significant relationship between exports and carbon dioxide emissions.

\section{Notes}

1 Author’s e-mail address: bosupengmpho@hotmail.com

\section{References}

Alshehry, A.S., Belloumi, M. (2015), Energy consumption, carbon dioxide emissions and economic growth: the case of Saudi Arabia, Renewable and Sustainable Energy Reviews, Vol. 41, pp. 237-247, doi.org/10.1016/j. rser.2014.08.004

Asemota, O.M., Bala, D.A. (2011), A Kalman Filter approach to Fisher effect: Evidence from Nigeria, CBN Journal of Applied Statistics, Vol. 2, No. 1, pp. 71-91.

Caporale, G.M., Pittis, N. (1999), Efficient estimation of cointegrating vectors and testing for causality in vector autoregression., Journal of Economic Issues, Vol. 13, pp. 3-35.

Chang, Ch-P., Berdiev, A.N., Lee, Ch-Chi. (2013), Energy exports, globalization and economic growth: The case of South Caucasus, Economic Modelling, Vol. 33, pp. 383-346. 
Deng, W., Chen, D., Huang, M., Hu, J., Chen, L. (2015), Carbon dioxide deliming in leather production: a literature review, Journal of Cleaner Production, Vol. 87, pp. 26-38.

Dickey, D.A., Fuller, W.A. (1979), Distribution of the estimators for autoregressive time series with a unit root, Journal of the American Statistical Association, Vol. 74, No. 366, pp. 427-431.

Elliott, G. (1998), On the robustness of cointegration methods when regressors almost have a unit root, Econometrica, Vol. 66, No. 1, pp. 149-158, doi:10.2307/2998544.

Engle, R.F., Granger, C.W. (1987), Cointegration and error correction: representation, estimation, and testing, Econometrica, Vol. 55, No. 2, pp. 251-276, doi:10.2307/1913236

Granger, C.W. (1981), Some properties of time series data and their use in econometric model specification, Journal of Econometrics, Vol. 55, pp. 251-276, doi:10.1016/0304-4076(81) 90079-8

Granger, C.W.J. (1969), Investigating causal relations by econometric models: cross spectral methods,. Econometrica, Vol. 37, No. 3, pp. 424-438, doi:10.2307/1912791

Granger, C.W.J., Weiss, A.A. (1983), Time series analysis of error correction models, in: S. Karlim, T. Amemiya, L.A. Goodman, Studies in Economic Time Series and Multivariate Statistics, Academic Press, New York, doi:10.1016/b978-0-12-398750-1.50018-8

Granger, C.W.J., Engle, R.F. (1985), Dynamic model specification with equilibrium constraints, University of California, San Diego.

Gregg, J.S., Andre, R.J., Marland, G. (2008), China: emissions pattern of the world leader in $\mathrm{CO}_{2}$ emissions from fossil fuels consumption and cement production, Geophysical Research Letters, Vol. 35, LO8806, available at: http://www.theglobaleconomy.com/, accessed: October 10, 2015.

Hovarth, W., Watson, M. (1995), Testing for cointegration when some of the cointegrating vectors are prespecified, Econometric Theory, Vol. 11, No. 5, pp. 984-1014, doi:10.1017/s0266466600009944

Jafari, Y., Othman, J., Nor Abu, H. S M. (2012), Energy consumption, economic growth and environmental pollutants in Indonesia, Journal of Policy Modelling, Vol. 34, pp. 879-889.

Johansen, S. (1988), Statistical analysis of cointegration vectors, Journal of Economic Dynamics and Control, Vol. 12, pp. 231-254, doi:10.1016/0165-1889(88) 90041-3

Johansen, S. (1991), Estimation and hypothesis testing of cointegration vectors in Gaussian Vector Autoregressive models, Econometrica, Vol. 59, No. 6, pp. 1551-1580, doi:10.2307/2938278

Johansen, S., Juselius, K. (1990), Maximum likelihood estimation and inference on cointegration with applications to the demand for money, Oxford Bulletin of Economics and Statistics, Vol. 52, No. 2, pp. 169-210, doi:10.1111/j.1468-0084.1990.mp52002003.x

Kahrl, F., Roland-Holst, D. (2008), Energy and exports in China, China Economic Review, Vol. 19, pp. 649-658.

Lee, J.W., Brahmasrene, T. (2013), Investigating the influence of tourism on economic growth and carbon emissions: evidence from panel analysis of the European Union, Tourism Management, Vol. 38, pp. 69-76, dx.doi. org/10.1016/j.tourman.2013.02.016

Loganathan, N., Shabaz, M., Taha, R. (2014), The link between green taxation and economic growth on $\mathrm{CO}_{2}$ emissions: fresh evidence from Malaysia, Renewable and Sustainable Energy Review, Vol. 38, pp. 1083-1091, dx.doi.org/10.1016/j.rser.2014.07.057

Mavrotas, G., Kelly, R. (2001), Old wine in new bottle: testing causality between savings and growth, The Manchester School Supplement, pp. 97-105.

Omri, A. (2013), $\mathrm{CO}_{2}$ emissions, energy consumption and economic growth in MENA countries: evidence from simultaneous equation models, Energy Economics, Vol. 40, pp. 657-664, dx.doi.org/10.1016/j.eneco.2013.09.003 Park, J.Y. (1990), Testing for unit roots and cointegration by variable addition, Advances in Econometrics, Vol. 8, pp. 107-133. 
Park, J.Y. (1992), Canonical cointegration regression, Econometrica, Vol. 60, pp.119-144.

Phillips, P.C.B., Durlauf, S.N. (1986), Multiple time series regression with integrated processes. Review of Economic Studies, Vol. 53, pp. 473-495, doi:10.2307/2297602

Phillips, P.C.B., Hansen, B. E (1990), Statistical inference in instrumental variable with I (1) processes, Review of Economic Studies, Vol. 57, pp. 99-125, doi:10.2307/2297545

Phillips, P.C.B., Ouilaris, S. (1986), Testing for cointegration, Cowles Foundation Discussion Paper, No. 809.

Phillips, P.C.B., Park, J.Y. (1986), Asymptotic equivalence of OLS and GLS in regression with integrated regressors, Cowles Foundation Discussion Paper, No. 802.

Phillips, P.C.B., Perron, P. (1988), Testing for a unit root in time series regression, Biometrika, Vol. 75, No. 2, pp. 335-346, doi:10.2307/2336182

Rambaldi, A.N. (1997), Mutliple time series models and testing for causality and exogeneity: a review, Working Papers in Econometrics and Applied Statistics, No. 96. Department of Econometrics, University of New England.

Rambaldi, A.N., Doran, H.E. (1996), Testing for Granger non-causality in cointegrated systems made easy, Working Papers in Econometrics and Applied Statistics, No. 88. Department of Econometrics, University of New England.

Saikkonen, P. (1992), Estimation and testing of cointegrated systems by an autoregressive approximation, Econometric Theory, Vol. 8, No. 1, pp. 1-27, doi: 10.1017/s0266466600010720

Saikkonen, P., Lütkepohl, H. (2000a), Testing for the cointegrating rank of a VAR process with an intercept, Economic Theory, Vol. 16, pp. 373-406.

Saikkonen, P., Lütkepohl, H. (2000b), Testing for the cointegrating rank of a VAR process with structural shift, Journal of Business and Economic Statistics, Vol. 18, pp. 451-464.

Soytas, U., Sari, R. (2009), Energy consumption, economic growth, and carbon emissions: challenges faced by an EU candidate member, Ecological Economics, Vol. 68, pp. 1667-1675, doi:10.1016/j.ecolecon.2007.06.014

Stock, J.H. (1987), Asymptotic properties of least squares estimates of cointegration vectors. Econometrica, Vol. 55, No. 5, pp. 1035-1056, doi:10.2307/1911260

Stock, J.H., Watson, M.W. (1987), Testing for common trends, Working Paper in Econometrics, Hoover Institution, Stanford, CA.

Toda., H.Y., Yamamoto, T. (1995), Statistical inference in vector autoregressions with possibly integrated processes, Journal of Econometrics, Vol. 66, pp. 225-250.

Wang, C. (2013), Differential output growth across regions and carbon dioxide emissions: evidence from U.S. and China. Energy, Vol. 53, pp. 230-236, dx.doi.org/10.1016/j.energy.2013.02.044

Wolde-Rufael, Y. (2005), Energy demand and economic growth: the African experience, Journal of Policy Modeling, Vol. 27, pp. 891-903, doi:10.1016/j.jpolmod.2005.06.003

Xu, B., Lin, B. (2015), Carbon dioxide emissions reduction in China's transport sector: a dynamic VAR (Vector Autoregression) approach. Energy, Vol. 83, pp. 486-495.

Zapata, H, O., Rambaldi, A.N. (1997), Monte Carlo evidence on cointegration and causation. Oxford Bulletin of Economics and Statistics, Vol. 59, pp. 285-298.

Zhang, X.-P., Cheng, X.-M. (2009), Energy consumption, carbon emissions and economic growth in China. Ecological Economics, Vol. 68, pp. 2706-2712, doi:10.1016/j.ecolecon.2009.05.011

Zhixin, Z., Ya, L. (2011), The impact of carbon dioxide on economic growth in China. Energy Procedia, Vol. 5, pp. 1757-1761, doi:10.1016/j.egypro.2011.03.299 